
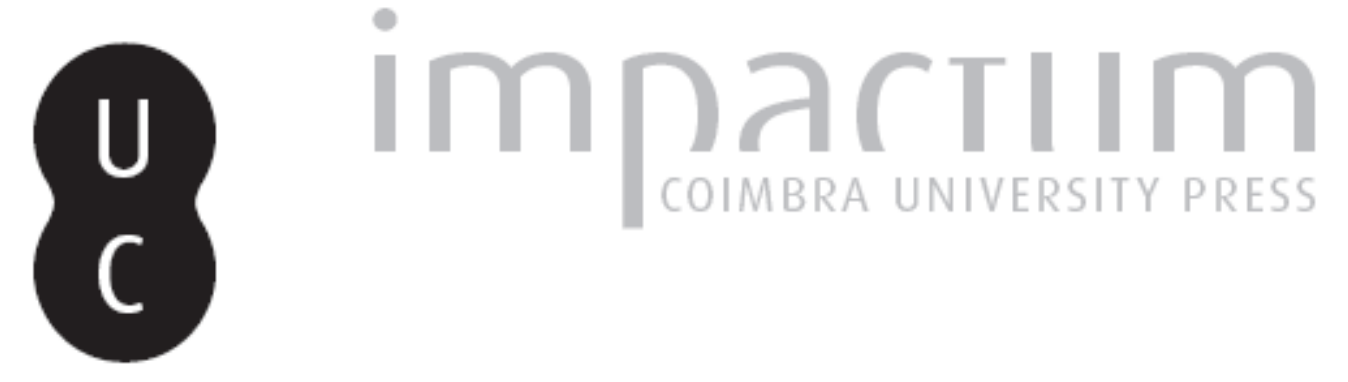

\title{
Os 20 anos da comunidade dos países de língua portuguesa na imprensa brasileira: discutindo as condições para uma communitas possível
}

Autor(es): $\quad$ Góes, José Christian; Antunes, Elton

Publicado por: Imprensa da Universidade de Coimbra

URL persistente:

URI:http://hdl.handle.net/10316.2/39637

DOI:

DOI:http://dx.doi.org/10.14195/2183-5462_29_11

Accessed : $\quad$ 26-Apr-2023 15:31:39

A navegação consulta e descarregamento dos títulos inseridos nas Bibliotecas Digitais UC Digitalis, UC Pombalina e UC Impactum, pressupõem a aceitação plena e sem reservas dos Termos e Condições de Uso destas Bibliotecas Digitais, disponíveis em https://digitalis.uc.pt/pt-pt/termos.

Conforme exposto nos referidos Termos e Condições de Uso, o descarregamento de títulos de acesso restrito requer uma licença válida de autorização devendo o utilizador aceder ao(s) documento(s) a partir de um endereço de IP da instituição detentora da supramencionada licença.

Ao utilizador é apenas permitido o descarregamento para uso pessoal, pelo que o emprego do(s) título(s) descarregado(s) para outro fim, designadamente comercial, carece de autorização do respetivo autor ou editor da obra.

Na medida em que todas as obras da UC Digitalis se encontram protegidas pelo Código do Direito de Autor e Direitos Conexos e demais legislação aplicável, toda a cópia, parcial ou total, deste documento, nos casos em que é legalmente admitida, deverá conter ou fazer-se acompanhar por este aviso.

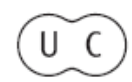




\section{Media Jornalismo}

\section{MÉDIA E COLONIALISMO(S)}


OS 20 ANOS DA COMUNIDADE DOS PAÍSES DE LÍNGUA

PORTUGUESA NA IMPRENSA BRASILEIRA: DISCUTINDO AS

CONDIÇÕES PARA UMA COMMUNITAS POSSÍVEL

\section{YEARS OF THE COMMUNITY OF PORTUGUESE LANGUAGE SPEAKING COUNTRIES IN THE BRAZILIAN PRESS: \\ DISCUSSING THE CONDITIONS FOR A POSSIBLE COMMUNITAS}

\section{JOSÉ CRISTIAN GÓES}

UNIVERSIDADE FEDERAL DE MINAS GERAIS, FACULDADE DE CIÊNCIAS SOCIAIS E APLICADAS, PROGRAMA DE PÓS-GRADUAÇÃO EM COMUNICAÇÃO SOCIAL

BELO HORIZONTE/MG - $5503199993-7131$

BRASIL

CRISTIANGOES_BRASIL@YAHOO.COM.BR

\section{ELTON ANTUNES}

UNIVERSIDADE FEDERAL DE MINAS GERAIS, FACULDADE DE CIÊNCIAS SOCIAIS E APLICADAS, PROGRAMA DE PÓS-GRADUAÇÃO EM COMUNICAÇÃO SOCIAL

BELO HORIZONTE/MG - 5503134095072

BRASIL

ELTUNES@UOL.COM.BR

\section{Resumo}

0 presente estudo analisa as informações que a imprensa brasileira vem divulgando acerca da Comunidade dos Países de Língua Portuguesa (CPLP), que completa 20 anos em 2016. Segundo as ideias de communitas trabalhadas por Roberto Esposito (2012), o que une os membros de uma comunidade é uma falta, uma carência, gerando uma obrigação, um dever recíproco e fraterno. Nessas condições, a CPLP pode ser imaginada como uma communitas possível? No caso do Brasil, o desafio começa pelo enfrentamento da invisibilização da comunidade. Nossa investigação revelou que, desde o início, a CPLP esteve ausente nos dois maiores jornais brasileiros: Folha de $S$. Paulo e 0 Globo. Até os poucos registros encontrados são exemplares para debater esse não reconhecimento. Todavia, as construções identitárias entre os povos da CPLP, as condições históricas comuns e a conjuntura contemporânea são potencialidades que provocam uma discussão sobre essa comunidade na perspectiva da communitas.

CPLP, comunidade, communitas, lusofonia, identidades. 


\section{Abstract}

As the Community of Portuguese Language Speaking Countries (CPLP) turns 20 years old in 2016, this article analyzes information published by the Brazilian press about this community. We propose a discussion on the sense of community, drawing on Roberto Esposito's (2012) ideas of communitas. According to Esposito an absence unites the members of a community, where some lack or neediness generates obligation and a reciprocal and fraternal duty amongst the members. Under such circumstances, is the CPLP able to be held as a possible communitas? In the case of Brazil, the immediate challenge is to face the community's invisibility. Our research has found that, in nearly 20 years, the CPLP has been absent of the two largest Brazilian newspapers: Folha de S. Paulo and O Globo, even though the few known records of them are copies that discuss this non-recognition. However, the identity constructions within the CPLP nations, the common historical conditions, and the contemporary environment are potentialities that encourage community building in the light of the communitas.

\section{KEYWORDS}

CPLP; community; communitas; lusophony, identities.

\section{INTRODUÇÃO}

Em 17 de julho de 2016, a Comunidade dos Países de Língua Portuguesa (CPLP) completou 20 anos que foi instituída. No entanto, a história comum dos povos que têm o português como língua oficial é marcada por uma longa construção identitária que remonta às expansões europeias dos séculos XV e XVI. Lembremos que o Brasil, por exemplo, é alvo da empresa imperialista portuguesa, mas com participações inglesas e espanholas. Na busca pelo "novo mundo", as nações europeias formavam consórcios geopolíticos e econômicos. Além dos colonizadores europeus, os brasileiros são resultado do sangue e do suor de índios, negros e mestiços escravizados e livres.

Ocorre que no rescaldo não programado dessas ações expansionistas emerge um caldo sócio-cultural que vai, umbilicalmente, atar metrópole e colônia de tal maneira que, mesmo depois da colônia se tornar independente, parece ser impossível dissociar os vínculos constitutivos com a metrópole. A língua, mesmo que assemelhada, será um dos tantos laços identitários que as ligam. Com o fim do período colonial, tomando-se por base à justificativa de um elo histórico e cultural, surgem organizações que tentam, ainda que indiretamente, perpetuar algum tipo de influência da ex-metrópole sob a ex-colônia. Nessa lógica aparecem a Organização Internacional da Francofonia (OIF), com 57 Estados de língua francesa; a Commonwealth Britânica, em que o inglês é oficial em 53 países; e a Comunidade dos Países de Língua Portuguesa.

A CPLP nasce em julho de 1996 e hoje é composta por Angola, Cabo Verde, Guiné Bissau, Guiné Equatorial, Moçambique e São Tomé e Príncipe, na África; Brasil, na América do Sul; Portugal, na Europa; e Timor Leste, na Ásia (ver Ilustração 1). Nessas nações, a língua portuguesa deve ser 0 idioma oficial, mesmo não sendo, em algumas, a mais falada, como nos países africanos e em Timor Leste. Ocorre que a CPLP, apesar de instituída em meados dos anos 1990, foi ensaiada desde 0 início do século XX para organizar o "mundo lusófono", tendo Portugal como o centro irradiador da ideia de lusofonia. 
Ilustração 1 - Mapa com a distribuição geográfica dos nove países da CPLP

Fonte: www.cplp.org

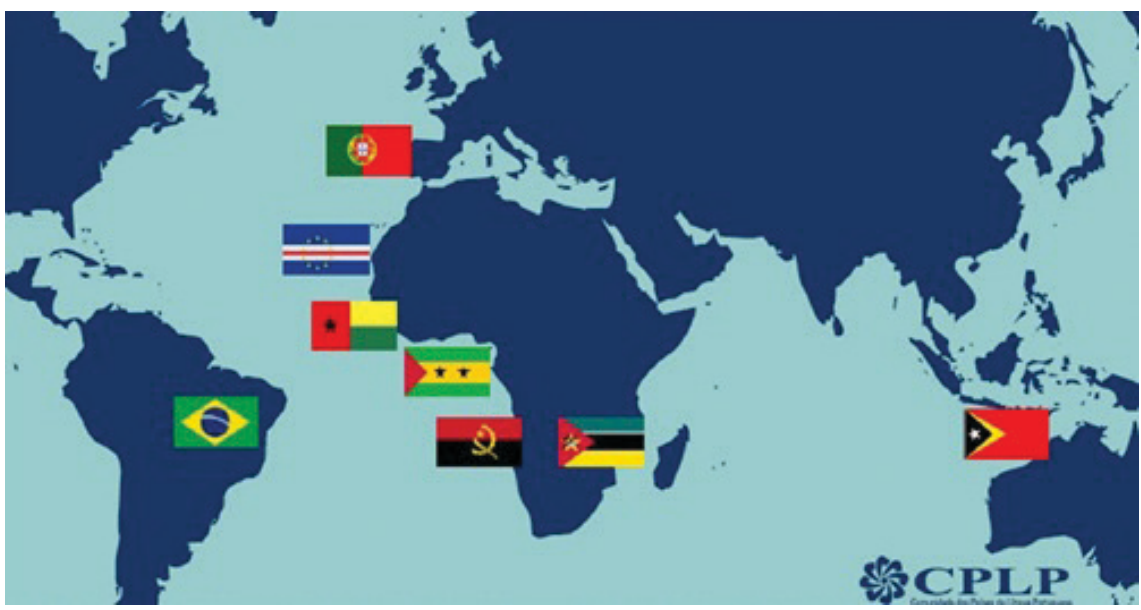

Mas se a CPLP surgiu no início para manter interesses portugueses sob as suas ex-colônias, ela também pode ser vista como uma ponte institucional para que os países mais pobres dessa comunidade possam ter acesso às promessas de uma globalização, principalmente a partir da ex-metrópole. Tendo ou não a proeminência de Portugal, 0 importante é que a ideia da CPLP como uma comunidade de fato circunscreve povos diferentes, mas que possuem fios histórico-identitários constitutivos deles mesmos e entrelaçados entre si. Assim, parece impossível pensar na constituição das nações e dos povos da CPLP sem considerar todos os seus atores em suas unidades e diversidades.

A questão é saber se podemos imaginar uma organização composta por países muito diversos em quatro continentes como uma "comunidade"? 0 que há de "comum" que faz existir a CPLP? De fato o que é a CPLP e que referências de comunidade podemos usar para melhor visualizá-la? 0 Brasil se reconhece nessa comunidade?

Uma das maneiras de responder a tais questões é compreender como a mídia informativa transforma a ideia de uma comunidade lusófona em conhecimento público. No escopo desse artigo, vamos examinar de que modo o noticiário brasileiro participa desse processo pela ótica dos jornais Folha de São Paulo e 0 Globo, investigando como o Brasil noticiou a CPLP nas quase duas décadas de sua existência. Para discutir tal abordagem jornalística, debatemos inicialmente a ideia de "comunidade" em meio aos processos globalizantes, percebendo tensões e contradições que a atravessam, mas logo avançando para o conceito de communitas, que para Roberto Esposito (2012)' é o "conjunto de pessoas unidas não por um 'mais', mas por um 'menos', uma falta, um limite que se configura como um penhor ou até mesmo um modo de carência a quem está 'afetado'" (Esposito, 2012: 29-30)2.

1 Todas as citações diretas de Esposito nesse trabalho foram traduzidas por nós.

2 “Conjunto de personas unidas no por un 'más', sino por un 'menos', una falta, un límite que se configure como un gravamen, o incluso una modalidad carencial, para quien está 'afectado'". 
Por fim, ao observarmos as construções históricas sobre a lusofonia, cotejamos as possibilidades de imaginar a CPLP como uma experiência de comunidade de fato. Essa condição necessita que entendamos o "comum" na comunidade como uma "carência", uma "falta", o que vai implicar necessariamente em um dever, numa obrigação, numa dívida entre todos. Com a investigação sobre as notícias, poderemos perguntar como o jornalismo tem oferecido ou não elementos para pensar a CPLP como communitas.

\section{DAS CRISES AO FORTALECIMENTO DA COMUNIDADE}

Mesmo sendo um processo instável, aberto e permeado por assimétricas disputas de poder em torno de suas definições, as identidades criam laços de identificação em que os sujeitos se reconhecem com mais ou menos familiaridade a alguns do que a outros. Quanto mais próximo dos parecidos a mim, mais vai emergir um sentimento de pertencimento a um grupo, a uma comunidade (Hall: 2006; 2013). Por isso, muitas vezes, as ideias de identidade e comunidade fazem referências sempre a uma essência (a família, o local de nascimento, etc.) que será partilhada pelos mesmos, definindo e caracterizando um agrupamento pelo que ele tem de comum, pelo que lhe é próprio.

Além de reforçar que identidades e comunidades estão num movimento incessante de construção e reconstrução, Bauman (2003) já alertava que a comunidade não se define apenas por reunir pessoas que têm algo em comum, mas também como um lugar em que "podemos contar com a boa vontade dos outros", onde "nunca somos estranhos entre nós", condições imaginadas que apontam que essa comunidade "esteve sempre no futuro", uma espécie de "paraíso perdido" (Bauman, 2003: 9).

Desde os primórdios dos processos da globalização do capital, ainda no século XVI, e com o avanço da Modernidade, encurtando o espaço e o tempo, a concepção de comunidade vem se transformando, mas, ao que parece, dentro de um movimento cíclico. Sousa Santos (1994: 33) afirma que a ruína da comunidade na Era Moderna produziu um grande vazio social e que o Estado tentou preenchê-lo, porém, sem jamais conseguir. Não é coincidência que esse processo se confirma com a supremacia dos modelos liberais, com a consolidação do capitalismo, das lógicas de mercado, da propriedade individual. Temos, assim, os triunfos de uma subjetividade individual, do nascimento da identidade-global, do cidadão-mundo e "quem sai perdendo é o princípio da comunidade" (Sousa Santos, 1994: 34), o que não implica no fim da coletividade, mas, ao contrário, contraditoriamente busca-se o seu reforço, como uma tentativa de retorno a uma identidade perdida.

Em certo sentido, falar em "comunidade" no mundo contemporâneo associa-se ao primitivo, ao atraso numa clara oposição ao Moderno, ao Pós-Moderno. No entender de Giddens (2002), essa visão vem da expansão imperialista do Estado-nação, que busca alargar suas fronteiras aonde pudesse no "novo mundo", reforçando 0 poder do capital. Todavia esse é um processo ambíguo em que, de um lado, difunde-se a sensação de unificação planetária sob o comando de impérios, mas dentro deles, as comunidades locais, sentindo-se abandonadas, passam a se organizar e ganhar cada vez mais relevo. Por isso, Giddens (2002: 27) propõe pensarmos em uma "dialética do local e do global".

Hall (2006: 69) diz que as nações jamais foram autônomas, sendo o capitalismo elemento da economia mundial e não das nações. Em outras palavras, o avanço do 
capital nunca viu fronteiras e isso terá, segundo 0 autor, três consequências para as comunidades nacionais: a "desintegração", por conta de certa homogeneização cultural pós-moderna e global; mas, contraditoriamente, o "reforço" de identidades locais, até também como forma de resistência à globalização; e, por fim, como síntese desse processo, o surgimento de novas identidades, aparentemente sem amarras. Hall sustenta que, ao mesmo tempo em que a globalização esfacela as formas nacionais de identidade, tentando apagar laços de identificação, criando a ilusão do cidadão global, ela também resgata identidades locais, bem mais tradicionais (Hall, 2006: 73). Essas identidades vão se abrigar em comunidades que prometem proteger certas tradições.

Com a imaginada aldeia global, a identificação nacional que faz referências aos lugares, eventos, símbolos, heróis passa a não ter muito sentido. A ideia de uma identidade nacional parece não existir. Em razão das novas tecnologias, fala-se numa rede planetária, única, global. Todavia, o capital para se realizar como poder exige a diferença, isto é, o outro descapitalizado e subalterno. É nessa condição que se admite e vai associar o outro à comunidade, vista como o lugar do pobre, do estranho, do esquisito, um espaço para fixar fronteiras no sentido do controle, da vigilância. Ao fabricar o outro, as elites internacionais também se organizam em grupos para proteção de seus interesses. Os blocos econômicos dos países ricos e seus bancos mundiais materializam esse quadro. Esses grupos continuam a não ver fronteiras no avanço de seus interesses. Entre as nações pobres, permitem-se até a existência de comunidades culturais, exóticas, turísticas, porém marcadas pela imobilidade de seus povos e pela vigilância das nações mais ricas.

Não é sem propósito que o chamado multiculturalismo atende, em certo sentido, a essa lógica, mantendo intocados certos locais em que há uma diferença para ser vista como objeto. Lembra Hall (2006) que a fascinação com a etnia e a alteridade será até alvo de mercantilização. Esse outro ainda atende aos interesses globais se for um corpo dócil a produzir a baixo custo, perpetuando um processo de colonialidade. Esse quadro desvela centros e periferias de um ilusório mundo global. Na prática, algumas nações na Ásia, na América Latina e na África são politicamente independentes, "mas, sob muitos aspectos, continuam tão dominadas e dependentes quanto eram na época em que viviam governadas diretamente pelas potências européias" (Said, 2011: 56).

A questão é que a propagada globalização festeja o "fim das fronteiras" e, assim, parece incontornável, em algum momento, o encontro entre centros e periferias. Será percebido nesse momento que a promessa do consumo global não se realiza para todos, para os mais pobres, ao contrário dos mais ricos. Nessa tensão, afloram as identidades buscando, numa ponta, a liberdade, a segurança e a proteção para o capital e contra o outro, isto é, existe uma "forte reação defensiva daqueles membros de grupos étnicos dominantes que se sentem ameaçados pela presença de outras culturas" (Hall, 2006: 85). Na outra ponta, há uma luta para ser inserido no mundo visível. Esse é um percurso movido por medos e desconfianças, pela fixação de violentas fronteiras entre o nós e os outros, emergindo racismos e xenofobias.

Assim, em tempos globalizantes temos as "novas" comunidades de fantasia global e local, muitas a desenvolver princípios mais fundamentalistas e que reforçam 0 outro, a diferença, o estrangeiro, os de fora. Essa comunidade "pós-moderna" parece 
retomar, em certo sentido, princípios fixos, biológicos, imutáveis, seguindo na contramão de um conceito que prevê a comunidade como um lugar em que os elos entre seus membros não são a propriedade em comum, uma identidade, mas uma falta, uma carência que exige a ação, o dever, a tarefa, o compromisso fraterno e recíproco de todos para com todos.

\section{UMA COMMUNitAs É POSSÍVEL?}

Ao refletir sobre a globalização, Milton Santos (2000) defende a tese de que esse processo é reversível, apesar da lógica do capital propagandear o contrário. Para esse autor, a mesma força que constrói "um mundo confuso e perverso, pode vir a ser uma condição da construção de um mundo mais humano" (Santos, 2000: 85). No entanto, ele aposta que essas transformações não virão dos centros, mas das margens. "Na Ásia, na África e mesmo na América Latina, a vida local se manifesta ao mesmo tempo como uma resposta e uma reação a essa globalização" (Santos, 2000: 75). Sua justificativa é que "gente junta cria cultura" e produz uma vizinhança que valoriza "a experiência da escassez e a experiência da convivência e da solidariedade" (Santos, 2000: 70). Sousa Santos (1994) segue nessa trilha. Festeja as culturas e identidades de fronteira porque elas alimentam-se dos fluxos que as atravessam. "É uma porta de vai-e-vem, e como tal nunca está escancarada, nem nunca está fechada" (Sousa Santos, 1994: 50).

É nessa experiência solidária da troca de experiências que Bauman (2003: 19) sugere uma "comunidade ética", centrada em compromissos e "direitos inalienáveis e obrigações inabaláveis". Contudo, esse autor chama atenção de que ela está inserida em expectativas de um permanente diálogo, o que significa dizer que essa "comunidade de entendimento comum, mesmo se alcançada, permanecerá, portanto, frágil e vulnerável, precisando para sempre de vigilância, reforço e defesa" (Bauman, 2003: 19).

São essas as condições que nos levam à compreensão de comunidade em Esposito (2012). Esse autor vai buscar a etimologia da palavra "comunidade" na língua latina, encontrando a communitas e, diferentemente do que se imagina, o que há de comum na comunidade, caracterizando-a, não é um algo que seus membros têm como próprio, como essência, uma identidade. 0 que dará o sentido de comunidade como communitas é um dever, uma obrigação, uma dívida recíproca de todos para com todos. Ela é a coexperiência na busca do bem comum, em que a obrigação de todos para com todos é o elemento de ligação. Ressaltamos ainda que essa comunidade não tem delimitações geográficas, 0 que já elimina a possibilidade de fronteiras que lhe dêem forma.

As atenções de Esposito (2012) voltaram-se ao termo "comum" (cum + munus) da comunidade, sendo o cum (com) aquilo que nos coloca uns diante de todos, numa plena relação, isto é, aquilo que nos possibilita experienciar o estar juntos. Já o munus tem variadas possibilidades de tradução, mas todas giram em torno das mesmas questões. Munus pode ser onus (ônus), officium (Ofício) e donum (dom ou doação).

Esse autor relembra que nossa ideia de comunidade ainda é aquela em que pessoas se reúnem em torno de algo em comum, o que é próprio delas; um predicado que qualifica os membros de um mesmo conjunto (Esposito, 2012). Em outras palavras, essa ideia de comunidade produz uma qualidade que se agrega à "natureza" das pessoas, fazendo-as sujeitos da organização. Mas, "em todas as línguas neolatinas, 
e não somente nelas, 'comum' (commun, comune, common, kommun) é o que não é próprio, começando ali, onde o próprio termina" (Esposito, 2012, p. 25) [grifo do autor].

De fato, o "próprio" remete à propriedade, ao proprietário, à posse, ao privado, enquanto o "comum", como ensina Esposito, traz a ideia oposta, ou seja, o que não é mais de um, que é de muitos, que remete ao público, a todos. Assim, comum associado ao próprio apaga o munus, o dever, a doação, que são sinônimos de obrigação e de função, condições que vão aproximar, implicar e entrelaçar os membros da comunidade numa retribuição gratuita. Ao participarmos da comunidade estamos implicados (cum) com o munus, com a obrigação, com o ônus de retribuir, "seja em forma de bens, ou em forma de serviços (officium)" (Esposito, 2012, p. 27)4.

Tomando-se por base Esposito (2012), podemos dizer que a comunidade realiza-se nas relações, numa experiência viva entre doador e donatário, personagens em um mesmo Ser, sem possibilidade de separação entre essas tarefas. Ou seja, não há espaço para o eu, mas apenas para a communitas. Há "reciprocidade, ou 'mutualidade' (munus-mutuus), de um dar que determina entre 0 um e 0 outro um compromisso, e digamos também um juramento, comum" (Esposito, 2012: 28-29) ${ }^{5}$.

No entanto, esse autor percebe que a communitas necessita do contrapeso, caso contrário, torna-se totalitária ao sufocar o indivíduo. Como conceber a comunidade sem reconhecer a subjetividade dos seres que a compõem? É aqui que Esposito (2005) encontra transitando na communitas sua condição dialética: a immunitas. Enquanto o communis tem obrigações e deveres, o immunis reconhece-se isento, sem nenhuma obrigação. Os ingratus sentem-se "dispensados da dívida que os une uns aos outros, estão liberados do contato que ameaça a sua identidade e sua individualidade e de possibilidades que os exponha a um possível conflito com o seu vizinho" (Paiva, 2012: 73). Lembra em tempo Esposito (2012: 30) ${ }^{6}$ que "a communitas está ligada ao sacrifício de uma compensação, enquanto a immunitas implica no benefício da dispensa". Esse autor diz que o vínculo

[... ] imunidade e comunidade não se faz somente como sendo uma o fundo da outra, um fundo de contraste, mas também o objeto que contém a outra. Segundo este enfoque, não se deve perder de vista a circunstância de que a imunidade, enquanto categoria privativa torna-se importante não só como uma modalidade precisamente negativa da comunidade. Do mesmo modo que a comunidade parece hoje imunizada, atraída e engolida por completo pela forma do seu oposto. Em última instância, a imunidade é o limite interno que corta a comunidade dobrando-a sobre si próprio em uma forma que resulta às vezes constitutiva e destitutiva (Esposito, 2005: 19)7.

3 "En todas las lenguas neolatinas, y no solo em ellas, 'comum' (commun, comune, common, kommun) es lo que no es proprio, que empieza allí donde lo próprio termina".

4 "(...) sea em términos de bienes, ou en tperminos de servicio (officium)".

5 "(...) reciprocidad, ou 'mutualidad' (múnus-mutuus), del dar que determina entre el uno y otro un compromiso, y digámoslo también un juramento, común".

6 "La communitas está ligada al sacrificio de la compensatio, mientras que la immunitas implica el beneficio de la dispensatio".

7 "[... inmunidad y comunidad haciendo de una no sólo el fondo con el que contrasta, sino también el objeto y el contemdo de la otra. Según este enfoque, no debe perderse de vista la circunstancia de 
Percebemos que a communitas carrega constitutivamente uma espécie de "dom de morte" da subjetividade individual. Se a communitas "ameaça, como tal, a integridade individual dos sujeitos, a única alternativa é 'imunizar-se'" (Esposito, 2012: 41)8. É como um corpo a produzir anticorpos contra o vírus. 0 que é central é perceber que 0 "indivíduo" agirá contra o comum, contra a comunidade, o que pode ser um sintoma de uma contemporaneidade em que ele tenta se desligar "de todo laço social, de todo vínculo natural, de toda lei comum" (Esposito, 2012: 43) ${ }^{9}$. É fundamental ressaltar que a comunidade como communitas não é absoluta, sofrendo a tensão do indivíduo.

Essa discussão leva-nos a refletir que "comunidade" é experiência de uma busca, uma expectativa, faz-se em devir, porém ela é a própria e profunda tensão entre a sua plena e impossível realização em si mesma em razão da immunitas que a atravessa.

Independentemente desse necessário jogo de forças, consideramos fundamentais os aspectos levantados por Esposito (2012) quando da compreensão da comunidade que se constrói não por algo próprio e comum entre seus membros, mas pelas obrigações, deveres recíprocos e fraternos entre todos. Para Sodré (2014), a distinção entre comum e comunidade não atualiza institucionalmente o "comum originário, mas algo em que sempre estamos na medida em que sempre nos comunicamos, no interior da distribuição dos lugares e das identificações constitutivas do laço coesivo" (Sodré, 2014: 209). Cada forma de comunidade possível instauraria um novo comum.

Nessas condições, refletir sobre a communitas perturba o núcleo do modelo globalizante porque 0 outro não é tido como a diferença a ser combatida, mas entendido como o par, o que não implica no mesmo, no igual, no idêntico, mas no semeIhante que acolhe as particularidades culturais em um processo de partilha. Assim, retomamos a questão: a CPLP pode ser uma communitas possível?

\section{Communitas Lusófona e CPLP}

Se em razão dos processos globalizantes a ideia de uma comunidade nacional fica comprometida, parece impossível pensar em uma comunidade transnacional, ou melhor, transcontinental, baseada numa língua assemelhada, como é o caso da CPLP. Ocorre que o trânsito identitário dos povos de língua portuguesa é muito mais complexo, amplo e profundo do que o idioma. A língua partilhada tem grande peso, mas não sustenta por si só toda ideia de comunidade. Sua constituição é profundamente atravessada pelo idioma, mas também por uma série de outros elementos históricos, de relações sócio-econômicas, por um sistema de escravidão nas colônias portugueses que perdurou por mais de 320 anos, pela intensa mestiçagem,

que la inmunidad, en cuanto categoria privativa, no adquiere importância más que como modalidad, precisamente negativa de la comunidad. Del mismo modo en que, desde um ángulo de visión especularmente inverso, la comunidad parece hoy estar inmunizada, atraída y engullida por completo en la forma de su opuesto. En última instancia, la inmunidad es ellímite interno que corta la comunidad replegándola sobre sí en una forma que resulta a la vez constitutiva y destitutiva".

8 "[...] amenaza en cuanto tal la integridad individual de los sujetos que relaciona, la única alternativa es inmunizarse".

9 "[...] de todo lazo social, de todo vínculo natural, de toda ley común". 
pela religião, ou seja, as nações e os povos que formam a CPLP têm outros fortes componentes constitutivos e entrelaçados entre eles.

Dessa forma, vislumbramos algumas condições para que a CPLP possa ser uma experiência de communitas, conforme observamos em Esposito, o que exige, de saída, a sua visibilização e o reconhecimento dos traços sócio-históricos e de pertença entre os povos e nações. Enxergar-se nessa perspectiva implica na busca pela paridade comum e que impõe obrigações, uma dívida recíproca, uma retribuição fraterna (Esposito, 2012) entre todos os membros da CPLP. Nesse caso específico, faz-se necessário lembrar de que historicamente muitos dos povos africanos, timorenses, brasileiros e que foram inseridos na CPLP já vêm dando sua contribuiç̧ão na construção de uma riqueza cultural e de sentido do comum, mas o dever, a obrigação de retribruição para com muitos deles ainda é profundamente desigual, como denunciam indicadores que veremos a seguir.

0 desafio é pensar e construir a CPLP como communitas onde não podemos ser estranhos entre nós (Bauman, 2003). Imaginar essa instituição por essa ótica não é cair numa ilusória busca por uma essencialização, de constituição de uma propriedade que se fecha como uma forma de responder aos descentramentos advindos da globalização (Santos, 2000). Entendemos que a CPLP não tem vocação para esse tipo de um comum totalitário, de uma identidade pura e fixa porque ela é constituída de uma viva e intensa diversidade histórico-cultural, revelando-se incompatível com homogeneizações. Além disso, como observamos em Esposito (2012), a comunidade pensada como communitas recebe à força da condição immunitas, que garante a ação das individualidades, gerando uma tensão permanente contra as determinações coletivamente autoritárias. Reações e resistências pontuais entre os países da CPLP podem, ao nosso entender, ser um indício de um forte apelo à diversidade local, regional, e uma forma de enxergar o exercício da condição immunitas nessa mesma comunidade.

Pensar a CPLP como uma communitas possível nos leva a questionar a própria ideia de lusofonia que, de partida, tem uma gênese europeia ${ }^{10}$ e que, a depender do jogo de forças, pode comprometer a própria comunidade, porque ela - como communitas - não abriga um dono, um proprietário, a posse de algo, mas o "comum", ou seja, o mais de um, de muitos, de todos (Esposito, 2012). Por exemplo, há quem entenda a lusofonia como uma forma "particular de circular pelo mundo", como Alfredo Margarido (2000: 12), numa perspectiva positiva, isto é, como lugar onde se acolhem e se desenvolvem seus falantes. No entanto, para Eduardo Lourenço (2001: 181), a lusofonia não passa de uma ilusão portuguesa que mantém certa nostalgia imperial, ou seja, uma forma que os portugueses inventaram para não se sentirem sozinhos no mundo, tendo "nas sete ${ }^{11}$ partidas" um imaginário controle sob suas ex-colônias.

A ideia de lusofonia não é incompatível com a communitas, mas ela precisa ser compreendida em seu contexto, inclusive para superar os limites de suas frontei-

10 Na raiz da lusofonia está "luso", que remete a Portugal e à província romana do ano 29 a.C., a Lusitânia.

11 As "sete partidas" são os países que assinaram a primeira composição da CPLP, em 1996: Angola, Brasil, Cabo Verde, Guiné Bissau, Moçambique, Portugal e São Tomé e Príncipe. 
ras. Ela surge com mais clareza a partir da consolidação da Independência do Brasil, obrigando Portugal a reforçar suas ações imperiais junto as colônias na África e Ásia (Lourenço, 2001). Sugere-se que a lusofonia não nasce para dar sentido à "comunidade" lusófona, mas para tentar perpetuar um projeto imperialista português. De certa forma, atualizava-se a "missão civilizadora" europeia, vinda do século XVI, de converter, ensinar e proteger os bárbaros. Para Cabecinhas e Cunha (2003: 166), a partir da apologia do grande império, de um mundo e de uma civilização portuguesa, negava-se, assim, "a 'pequenez europeia' de Portugal". Superar essa lógica de vício e intenções de origem, de imaginar uma comunidade como propriedade e cujo sentido emana somente de um dos membros, é central para que a CPLP seja experienciada como communitas.

Antes mesmo do fim do período colonial, intelectuais portugueses e brasileiros ligados às estruturas de poder utilizaram da ideia de lusofonia para defender a criação de uma instituição que circundasse todo o mundo lusófono, mantendo-se de forma simbólica a influência de Portugal sobre as ex-áreas. No Brasil, Gilberto Freyre foi um dos defensores da teoria luso-tropicalista, bastante utilizada na ditadura portuguesa. A ideia era ter uma instituição centralizadora do pensar lusófono, também com o objetivo de produzir uma história oficial que revelasse, graças aos portugueses, um mundo de "harmonia entre os povos", retirando o peso da dominação e das barbáries contra índios, negros e mestiços. Para isso, a língua é imaginada como uma conexão espiritual, um "patrimônio comum", um "bem" que conforma uma "identidade específica dos países e povos que integram a CPLP" (Ilharco \& Murargy, 2014: 54).

Mesmo com as independências das colônias na África nos anos 1970, a lusofonia eurocêntrica já tinha deixado raízes em razão de um processo de assimilação que, de um lado, fixava imagens de civilizado ao europeu; e do outro, as marcas do primitivismo ao africano, ao brasileiro, ao colonizado de uma forma geral. Na prática, o reflexo desse processo é uma não-comunidade, mas o ajuntamento de países com muitas semelhanças linguísticas, no entanto, com profundas desigualdades sociais e econômicas. "Enquanto aos portugueses são abertos todos os caminhos e diluídas todas as fronteiras, aos outros (os negros) é destinado um papel específico num lugar com fronteiras bem delimitadas" (Cabecinhas, 2002: 98).

Assim, sugerimos que a lusofonia carrega um vício de origem ou, na expressão de Moisés Martins (2006), um "equívoco lusocêntrico". Maria Manuel Baptista (2006: 24) observa que a lusofonia assinala para Portugal "um lugar de 'não-reflexão', de 'não conhecimento', e sobretudo de 'não-reconhecimento', quer de si próprio, quer do outro".

Eduardo Lourenço (2001) retira o peso da língua como um patrimônio português. Para ele, "não é Portugal ou os outros países lusófonos que falam português, é a língua portuguesa que fala Portugal e esses outros países" (Lourenço, 2001: 189). Podemos pensar a lusofonia como uma linha de força discursiva que busca alinhavar pela língua, cultura, política e economia, povos e regiões que se utilizam de um idioma comum ou assemelhado, que certamente não homogeneiza os mais de 250 milhões de luso-falantes no mundo, mas que pode se configurar como um espaço de possibilidades identitárias por pertenças, fundamentadas nas histórias em comum. A lusofonia é um imaginário que vai além dos membros institucionalizados da CPLP, buscando ser 
um lugar privilegiado das diferenças, um ambiente rico de povos que se reconhecem pela língua, mas também por um terreno fértil de intensa diversidade cultural.

A longa relação colonial que se seguiu até meados dos anos 1970 entre Portugal e os países africanos, além de profundas diferenças sociais e econômicas resultantes dessa história, talvez expliquem o porquê da CPLP ter sido oficializada somente em 1996. As tentativas anteriores sempre foram modestas e cercadas de desconfiança neoimperialista portuguesa. Esse processo avançou quando, de fato, estrategicamente, o Brasil assumiu a dianteira na criação da CPLP. Depois de reuniões frustradas, o então embaixador brasileiro em Portugal, José Aparecido, conseguiu reunir em Lisboa, em 17 de julho de 1996, presidentes de sete países lusófonos para então ser instituída a CPLP. 0 contexto internacional em que ela foi criada era marcado pelo aparente fim da "guerra fria".

Ao nível interno, os nossos países enfrentavam desafios que revestiam-se de características muito distintas: Angola encontrava-se num contexto de guerra e 0 Brasil fazia face às dificuldades impostas pela crise financeira como resultado da introdução do plano real. Cabo-Verde lançava as bases para a afirmação da democracia pluripartidária e a Guiné-Bissau vivia uma experiência democrática dinâmica antes de mergulhar na presente era de conflitos. Moçambique recém-saído da guerra de desestabilização procurava estruturar-se, ensaiando os primeiros passos de democracia multipartidária e Portugal enfrentava os desafios da integração europeia. São Tomé e Príncipe conservava a estabilidade democrática não obstante a ocorrência de alguns episódios de conflitos a nível institucional e Timor-Leste lutava heroicamente para afirmar sua autodeterminação (Ilharco \& Murargy, 2014, p. 6).

Além da não contiguidade geográfica, os países e povos da CPLP se inserem em conjunturas políticas e econômicas muito diferentes, a exemplo de Portugal na União Europeia; do Brasil no Mercosul, dos países africanos e de Timor Leste a uma série de outras organizações. Além de não possuir peso econômico, também do ponto de vista político a atuação da CPLP é tímida, agindo em conflitos pontuais. As reuniões de boas intenções e acordos de cooperação estão aquém de um grupo de países que se imagina comunidade. Há enormes fronteiras econômicas e sociais entre eles, resultando, por exemplo, em mais de 28 milhões de pessoas afetadas todos os dias pela fome nas nações dessa comunidade (Ilharco \& Murargy, 2014: 7).

Dados do Instituto Nacional de Estatística (2015) de Portugal revelam que na CPLP o Índice de Desenvolvimento Humano ${ }^{12}$ sofre uma variação de 0,386 na Guiné-Bissau até 0,822 em Portugal. Enquanto em Portugal a expectativa de vida é de 77,4 anos, em Moçambique é de somente 42,1 anos. Na mortalidade infantil, as diferenças são relevantes. Na Guiné-Bissau são 90,9 mortes de crianças de até um ano por cada 100 mil nascidos vivos. Em Portugal é de 4,48, no Brasil, 14. Enquanto Portugal tem 95,4\% da população acima de 15 anos alfabetizada, na Guiné-Bissau são apenas 44,8\% (INE, 2015). Esses dados denunciam parte dos desafios para que essa comunidade se realize como communitas, porém, como observamos, estão nesses e em outros

120 IDH é medido de 0 a 1. Quando mais próximo de 1 (um) mais o país é considerado desenvolvido. 
dados os argumentos para se poder experienciar a CPLP como comunidade no sentido do dever, da obrigação, da dívida, da reciprocidade fraterna. Além desses grandes desafios, o que implica na responsabilização coletiva de todos da comunidade, em alguns casos, nem a própria CPLP é reconhecida. Podemos associar essa invisibilização e/ou indiferença à ação immunitas, isto é, que se isenta, que se dispensa, que não se obriga dentro da comunidade. Esta última dimensão pode ser vista na abordagem feita da CPLP nos dois dos mais importantes jornais diários brasileiros.

\section{A NÃO-COMUNIDADE NO BRASIL}

Nesse percurso em que problematizamos a CPLP buscamos investigar, pela ótica dos jornais Folha de São Paulo e O Globo, como o Brasil noticia essa comunidade. Partimos da compreensão de que o jornalismo encontra-se mergulhado na vida social e os modos como lida com os diferentes fenômenos sociais envolvem parte importante da nossa forma de compreender o mundo. Porém, se é inegável que os meios informativos configuram-se em um espaço privilegiado na atribuição de uma visibilização pública de assuntos e de atores na sociedade, tal aparição não é de todo homogênea. Entendemos o jornalismo como um dos operadores sócio-simbólicos que age com outros operadores e que o público realiza a experiência de remanejar os sentidos propostos, recolocando-os em ambientes culturais (Mouillaud, 1997). Ele é uma das experiências sociais que vai se tecendo na medida em que as relações iluminam os visíveis e, ao mesmo tempo, vai garantindo a produção de uma série de invisíveis. Quando falamos em experiência, referimo-nos a um dos modos de enxergar que "desperta o mundo", que nos implica nele e impede nossa fixação como meros espectadores (Merleau-Ponty, 2012).

Interessa-nos examinar se as notícias no Brasil sobre a CPLP jogam luzes ou apagam as alegadas ou eventuais pontes que nos unem histórica e identitariamente. As notícias nos jornais brasileiros Folha de $S$. Paulo e 0 Globo permitem refletir sobre a condição communitas da CPLP? 0 que aparece como a CPLP no Brasil? Metodologicamente vamos atuar em dois momentos articulados: primeiro vamos verificar 0 quantum, isto é, se existiram nos dois jornais notícias sobre a CPLP nesses quases 20 anos de sua existência. Nossa busca não é perceber a atuação isolada de um país da comunidade, mas reconhecer a notícia da e sobre a CPLP, sobre o conjunto. Depois de identificadas, passaremos para as análises de algumas das narrativas jornalísticas indicadas pelos dois periódicos, isto é, quais as ancoragens que essa comunidade na imprensa do Brasil, possibilitando ou não a reflexão sobre a communitas.

Nossa coleta ocorreu nos acervos digitalizados das edições impressas dos dois jornais, no período de $1^{\circ}$ de janeiro de 1996, seis meses antes da CPLP ser criada, e se estendeu até $1^{\circ}$ de janeiro de 2016, seis meses antes de completar 20 anos. Já vimos que o Brasil é um dos membros destacados da comunidade, com participação ativa na sua institucionalização, além de ter a maior população de língua portuguesa do mundo. A Folha e O Globo foram escolhidos porque são tidos como "jornais de referência", com expressiva projeção e influência nas operações de agendamento dos acontecimentos, e têm as maiores circulações no Brasil13. 0 slogan da Folha é "Um jornal a serviço do

13 Dados da Associação Brasileira dos Jornais (ABJ), em 2014, a Folha de S. Paulo teve a maior média mensal de circulação do Brasil, com 351.745 jornais, seguido de 0 Globo com 333.860 edições. 
Brasil", e 0 Globo é parte do maior grupo de mídia do país. Arbex Jr. (2001) lembra que esses jornais são empresas capitalistas que usam a retórica de porta-vozes dos "interesses da nação" na defesa do capital, da máxima redução do Estado, adotando 0 "discurso-para-o-mercado como estratégia empresarial e editorial" (Arbex Jr., 200: 141).

Como nosso objetivo era conhecer a ação direta desses jornais sobre a CPLP, definimos a categoria registros que abriga todas as notícias, entrevistas e editoriais em todos período da coleta. Foram excluídos artigos de opinião, notas em colunas, cartas do leitor e publicidade. Utilizamos como critérios de busca: CPLP, Comunidade dos Países de Língua Portuguesa, lusofonia, países lusófonos e nações lusófonas.

Os primeiros resultados encontrados nos 19 anos da CPLP e que vão atender a primeira fase de nosso percurso metodológico, foram apenas 92 pequenos registros em 0 Globo (ver Gráfico 1) e somente 94 na Folha (ver Gráfico 2).

\section{Gráfico 1 - Registros em 0 Globo em 19 anos da CPLP Fonte: Acervo de 0 Globo}

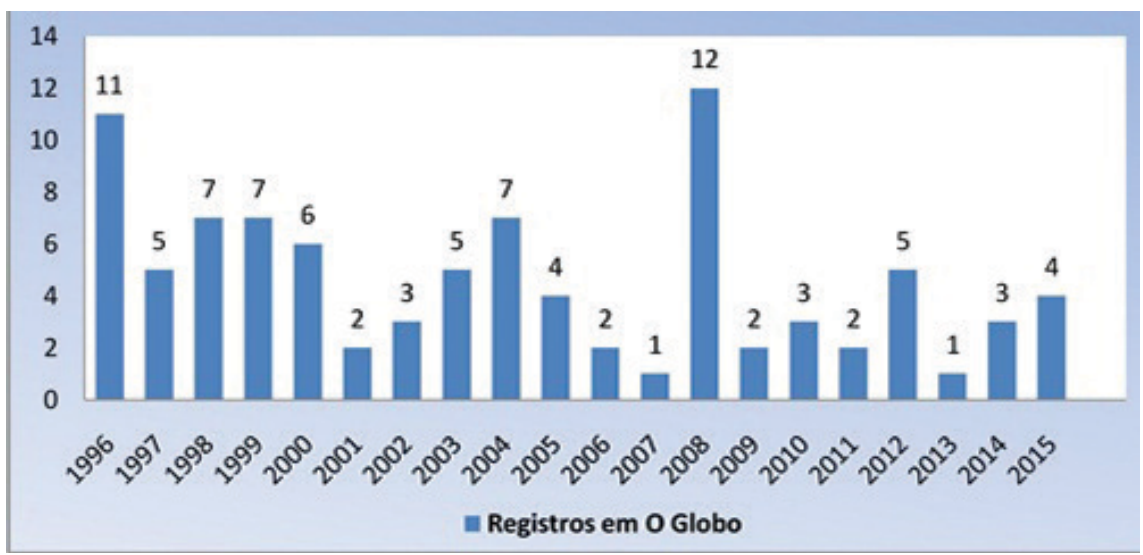

Gráfico 2 - Registros na Folha de S. Paulo em 19 anos da CPLP Fonte: Acervo da Folha de S. Paulo

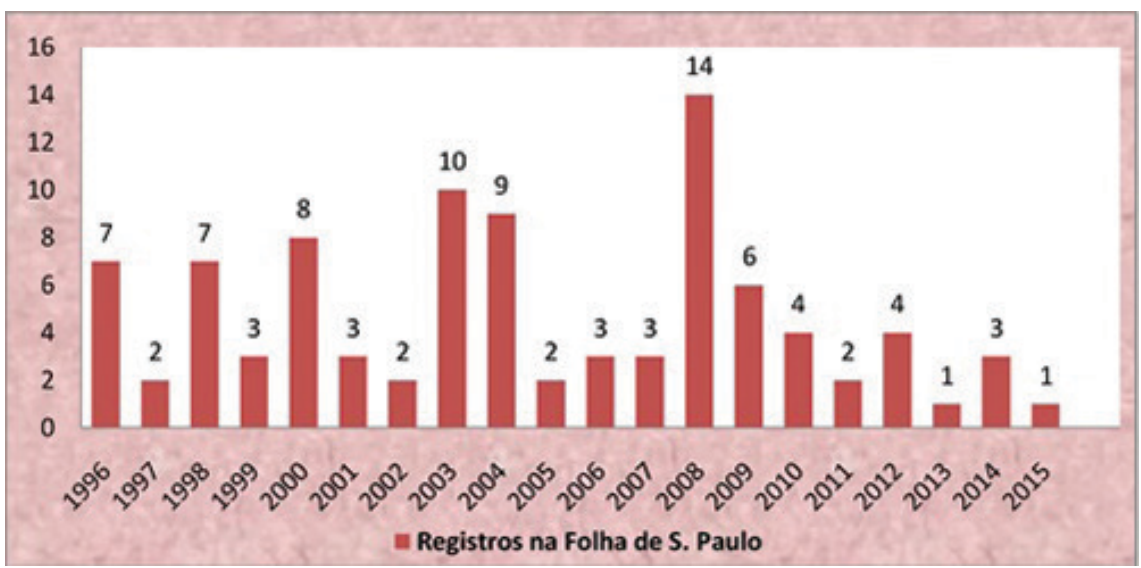


Podemos constatar o irrelevante número de notícias nos dois jornais de maior circulação no Brasil sobre a CPLP em quase 20 anos de existência. Levando-se em consideração esse longo período, as poucas e pequenas notícias sobre essa comunidade diluíram-se, perdendo-se nos anos e por entre as milhares de páginas nas mais de 6.935 edições de cada um desses periódicos por quase duas décadas. 0 ano de 2008 teve um repique porque nele o Parlamento Português aprovou uma nova versão para o Acordo Ortográfico na CPLP. A notícia repercutiu nos dois jornais brasileiros, em razão das alterações na escrita do português no Brasil. Além disso, 0 presidente Luis Inácio Lula da Silva sancionou esse "novo" acordo e marcou a data de entrada em vigor para $1^{\circ}$ de janeiro de 2009, o que não se confirmou. Além das notícias sobre o Acordo Ortográfico, 0 ano de 2008 também foi marcado por uma intensificação dos conflitos em Timor Leste, o que motivou algumas notícias sobre eles. No entanto, de maneira geral, constata-se uma marcante invisibilização da CPLP. Na prática, é como se essa comunidade não existisse para o Brasil. Os esparsos registros não possibilitam o reconhecimento da CPLP, não geram um quadro de inteligibilidade sobre ela entre seus leitores. Por exemplo, em 0 Globo, em média, foram só 4,8 registros por ano. Na Folha de S. Paulo, 4,9 notícias, revelando uma não-noticiabilidade muito parecida nos dois jornais (ver Gráfico 3).

Gráfico 3 - Registros comparativos em 0 Globo e na Folha nos 19 anos da CPLP Fonte: Acervos de 0 Globo e da Folha de S. Paulo

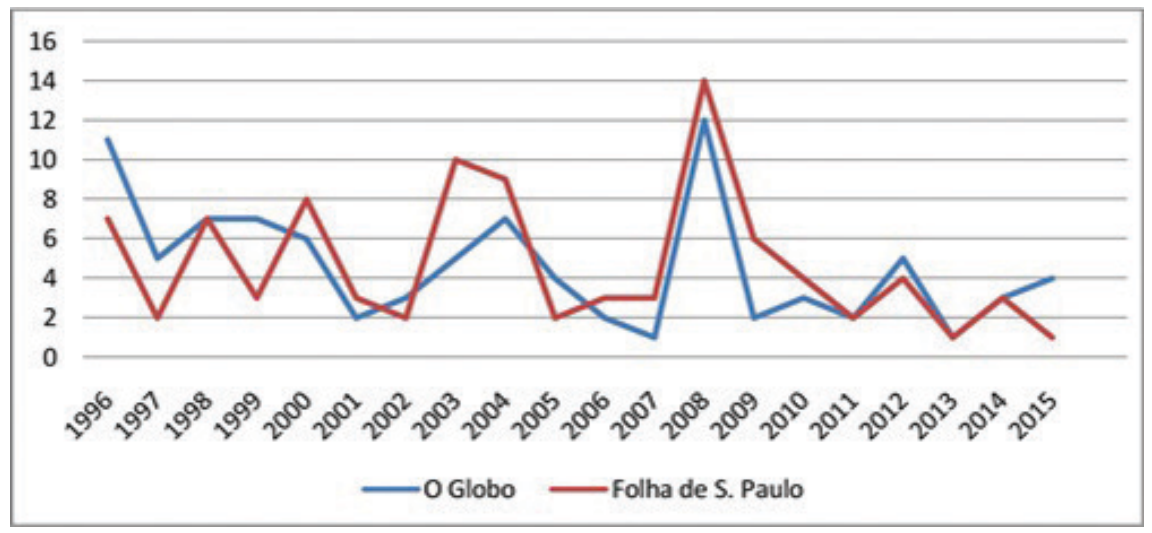

Com esses irrisórios registros num longo período e que se configuram como um processo de invisibilização, sugerimos um não reconhecimento da CPLP como uma comunidade da qual o Brasil faz parte. E não reconhecer-se como parte é uma ação de immunitas, daquele que se sente dispensado do dever recíproco com a communitas. Esse silenciamento prolongado tem seus fundamentos em nosso percurso histórico-identitário, que envolve Portugal e os países africanos dessa comunidade. Por exemplo, não é demais lembrar que o Brasil foi incluído no mapa do mundo no século XVI em razão da expansão mercantil europeia. A imposição de um destino - ser um lugar de exploração - norteou as ideias sobre o Brasil (Furtado, 2007). Porém, no longo período de não-nação e, até depois, fomos o outro, uma colônia portuguesa com ampla presença predatória europeia. As massas de gente inseridas 
no Brasil participaram dessa violenta lógica de exploração, e boa parte das relações humanas foi submetida a esse quadro, com reflexos nos processos identitários.

Em 1808, com a fuga da corte portuguesa para o Brasil e, depois, com a Independência, a referência identitária brasileira ideal passa a ser imaginada como europeia: homem, branco, culto e cordial. Para isso, foi fixada a diferença, o outro nesse mesmo espaço. Ele é negro, índio, pobre, crioulo, brasileiro mestiço, malandro, preguiçoso e que carrega a brasilidade maldita, o que explicaria, para a elite luso-brasileira, 0 nosso atraso. Basta lembrar as recorrentes e populares teses de negros como criminosos natos e da imigração nórdica para "embranquecer" o país ${ }^{14} \mathrm{e}$ solucionar seus males e que tomaram conta do debate público nacional, inclusive através da imprensa.

Imagina-se, assim, uma síntese de identidade nacionalque acerta os passos com a civilização europeia e, ao mesmo tempo, busca apagar os traços identitários com negros e índios. As narrativas dominantes vão conduzir uma identidade nacional que

pressupõe apagar algo que positivamente existia (a violência da colonização, o sistema escravagista e a multidão de negros que povoavam o país) e, ao mesmo tempo, pressupõe criar algo que positivamente nunca existiu: o consórcio harmonioso entre colonizador e o habitante natural da terra, o reconhecimento da resistência heróica das culturas autóctones, a convergência entre valores nativos e os valores da civilização ocidental (CUNHA, 2006: 101).

Aliados a esses aspectos, pontuamos outros que podem ajudar a perceber esse não reconhecimento pelo Brasil de uma comunidade de que faz parte. Somos uma das últimas nações a encerrar a escravidão negra. Nas vésperas do século XX, muitos de nós, negros e índios, éramos "seres sem alma". Foram mais de 320 anos de um dos mais cruéis sistemas escravocratas e isso não passaria incólume na memória social. Outro ponto é que as colônias portuguesas na África só deixaram essa condição há menos de 50 anos. Somente em 1975, por exemplo, Moçambique conquista a independência.

Há uma rejeição construída das lembranças desse quadro histórico-identitário e que se revela no Brasil pelo não reconhecimento como membro dessa comunidade. Não é demais relembrar que dos nove membros da CPLP, seis são africanos, alguns deles considerados de extrema pobreza. Além disso, há Timor Leste, também um pequeno, longínquo e pobre país asiático, que tornou-se independente só em 2002. Portugal, por sua vez, parece estar longe de ser uma das mais influentes economias mundiais. Esse quadro, alinhado a uma lógica econômica global que converge para países centrais do capitalismo, leva o Brasil a buscar contatos prioritários com países apontados como grandes potências, a exemplo dos Estados Unidos, da Alemanha, da Inglaterra, tentando inclusive inserir-se nesse grupo, até pleiteando uma cadeira permanente no Conselho de Segurança da ONU. Ou seja, essas pretensões brasileiras implicam, em certa medida, na rejeição, explícita ou não, do reconhecer-se como membro de uma comunidade que é composta majoritariamente por países pobres, muitos africanos e sem grandes expressões econômicas e geopolíticas.

14 Mais em RODRIGUES, N. (1957). As raças humanas. São Paulo: Progresso; FREYRE, G. (1946). Casa Grande \& Senzala. Rio de Janeiro: José Olympio; ROMERO, S. (1943). História da literatura brasileira. Rio de Janeiro: José Olympio; e outros. 
Avançamos na investigação para o segundo procedimento metodológico, ou seja, para saber como a CPLP foi noticiada nos jornais Folha de S. Paulo e em O Globo, mesmo diante dos poucos registros. Apesar de curtas e pontuais, eles são como rastros exemplares. Em geral, nas notícias buscou-se instituir um ambiente até de certo "compadrio" entre Brasil e Portugal e, ao mesmo tempo, de distância, rejeição e de vigilância com os africanos. Os casos de recusa são mais notados. Na Folha, em 77 dos 94 registros, isto é, em 81,9\% do total há rastros de distância e aversão. Em 0 Globo foram 79,3\%, ou seja, 73 das 92 notícias tinham marcas de desaprovação dessa comunidade em razão da "pobreza". Ou seja, inferimos que a ausência reiterada da CPLP nos jornais é ação identitária que atende a interesses do grande capital, ambiente em que transita o jornalismo da Folha e de 0 Globo. Quando há algum tipo de notícia, ela reforça essa concepção, assegurando uma ameaça pelo contágio negro e pobre. Vejamos alguns exemplos.

Em 16/07/1996, véspera da criação da CPLP, o presidente Fernando Henrique Cardoso concedeu uma entrevista ao Diário de Notícias, de Lisboa. Os jornais O Globo e a Folha a reproduziram. Nela (O Globo, p. 3), FHC afirma que a "mentalidade caipira e provinciana" do brasileiro "rejeita a globalização" (ver Figura 1). 0 presidente explica que essa "rejeição" ao mundo globalizado, moderno, que esse "atraso civilizacional" no Brasil é decorrente de nossa própria "mentalidade caipira e provinciana". Fernando Henrique Cardoso encontra uma justificativa histórica desse primitivismo: "sem dúvida nenhuma, a variante da mentalidade criolla", afirma ele.

Figura 1 - Recorte de parte da notícia em 0 Globo (0 País, 16/07/1996, p. 3)

Fonte: acervo de 0 Globo

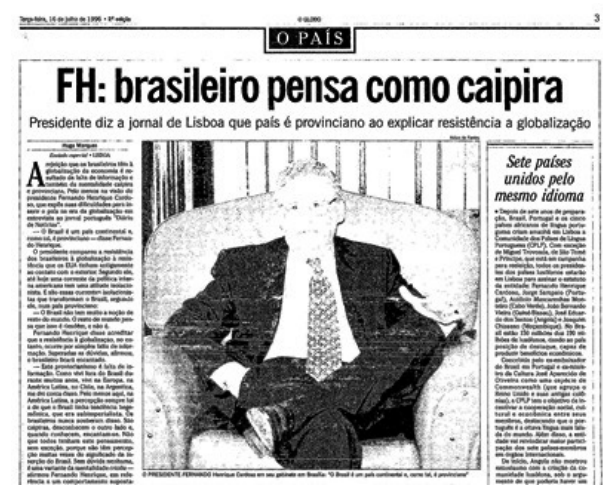

Seria essa a nossa carta de apresentação junto a uma comunidade com composição majoritária negra e africana e que nos constitui também como "povo brasileiro"? Esse registro faz emergir parte de um processo de formação dessa nação, revelando os negros e os crioulos como presenças incômodas às elites nacionais. Nessas condições, a CPLP parece nascer com um problema que impossibilita a communitas: a presença do outro, que deve ser eliminado em nome da inserção global da CPLP. Essa lógica no Brasil está perfeitamente alinhada a uma espécie de síntese da identidade nacional que vem sendo construída historicamente, associando-se à necessidade do moderno, apagando os traços de atraso (da pobreza, da escravidão, do negro), e buscando acertar os passos com um discurso civilizatório, oriundo do colonizador (Canclini, 1997). 
De maneira geral, os poucos registros nos dois jornais sobre a CPLP revelam uma entidade sem expressão econômica e política. Em 81,9\% dos registros na Folha de S. Paulo e em 79, 3\% das notícias em 0 Globo emergem indicações de importância e de superioridade política e econômica portuguesa e brasileira em relação aos países africanos e Timor Leste. Portugal e Brasil têm marcações de "senhores" dos destinos dos países africanos, que são sempre nomeados como pobres e entregues à corrupção e a ditaduras. Em 0 Globo de 26/07/2004 (0 País, p. 8), o presidente Lula sustenta a CPLP e afirma que essa entidade é uma "mostra do quanto Portugal e Brasil podem realizar juntos. Afinal, não nos faltam o que poderiam chamar de vantagens comparativas - a língua, a cultura, a afinidade natural". A Folha e 0 Globo chegam até a reconhecer o parentesco histórico-identitário entre o Brasil e a África, mas apenas para fixar os africanos como os "primos pobres dos brasileiros" (ver Figura 2). Para se configurar como uma communitas, esse exemplo pode ser um aceno dos limites entre a ação de comando e controle da comunidade, o que a inviabiliza, e a possibilidade de reconhecimento das dívidas históricas, dos deveres, das obrigações para com os países e povos mais pobres dessa comunidade.

Figura 2 - Recorte de parte da notícia em 0 Globo (0 País, 26/07/2004, p. 8)

Fonte: acervo de 0 Globo

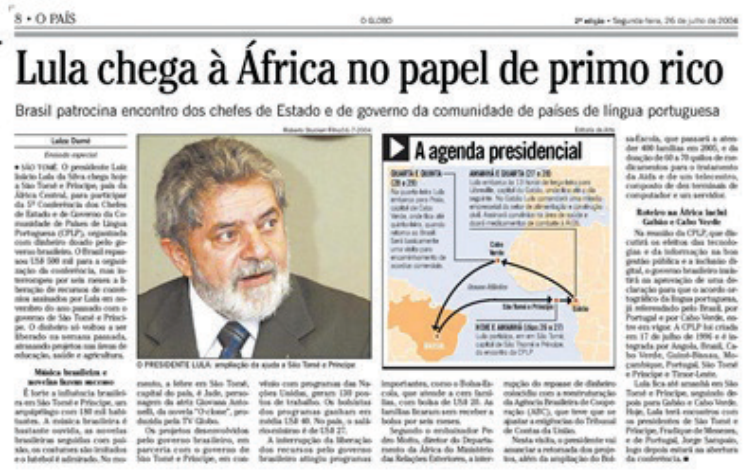

Em 13/04/1999, a Folha (Brasil, p. 6) trata da ida do presidente FHC a Lisboa. Diz o jornal: "A visita a Portugal seria mais de compadrio, dado o relacionamento histórico entre os dois países". Contextualiza a Folha: "A CPLP, que reúne, além de Brasil e Portugal, as antigas colônias africanas de Portugal". Ora, apenas os países africanos foram colônias? 0 jornal esquece que o Brasil também foi colônia e lembra do "compadrio" e do "relacionamento histórico" com Portugal.

A Folha de S. Paulo, em 15/07/1997 (ver Figura 3), traz um único registro para lembrar o primeiro ano da CPLP. E ele é exemplar. Informa que os países africanos de língua portuguesa querem que o Brasil estenda a eles o mesmo direito de livre circulação que é concedido aos portugueses, sem necessidade de visto nos consulados. Diz o jornal que o Brasil nega esse direito, alegando o perigo do tráfico de drogas. Esse registro foi publicado na página com as ocorrências policiais e isso não foi acaso. É a visibilização para o controle e a disciplina. Essa ação seletiva do medo-rejeição do outro africano aparece também em outras edições dos jornais, 0 
que impede de se imaginar a CPLP como uma communitas, inclusive ultrapassando a condição de immunitas, isto é, não há apenas uma dispensa de responsabilização, mas uma ação identitária de força, de controle e de vigilância dentro da CPLP, o que depõe radicalmente contra a própria ideia de comunidade.

Figura 3 - Recorte de parte da notícia na Folha de S. Paulo (Cotidiano, 15/07/1997, p. 4) Fonte: acervo da Folha

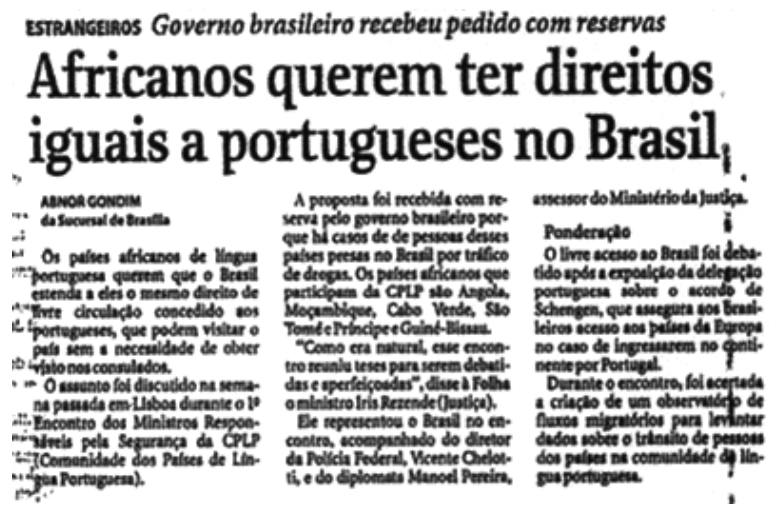

Os rastros das notícias nesses dois jornais revelam no Brasil a existência de uma relação diplomática fria, distante e protocolar, que atende as demandas pleiteadas pelos próprios países africanos. Dois aspectos chamam atenção a partir dos poucos registros: uma postura de indícios neoimperiais da política brasileira junto à África portuguesa e a insistente relação de troca dos apoios/acordos econômicos e sociais por votos no Brasil para uma cadeira permanente no Conselho de Segurança da ONU. Esta última é uma ancoragem que está presente em $89,2 \%$ de todos os registros sobre a CPLP nos dois jornais. As profundas relações histórico-identitárias entre os países dessa comunidade quase não foram levadas em conta nos pequenos registros nos dois jornais, emergindo como raros rastros em apenas $8 \%$ de total de notícias.

\section{CONCLUSÃo}

Em um cenário de globalização, onde princípios coletivos se esfacelam em razão de uma estética imaginada como identidade individual e global ao mesmo tempo e, por outro lado, por grupos locais que cultivam um fundamentalismo identitário, ambos com rigorosa oposição ao outro, pensar numa Comunidade de Povos de Língua Portuguesa como communitas, centrada numa obrigação recíproca, parece ser uma tarefa quase que impossível. Mas, são exatamente essas condições adversas e diversas que nos permitem perceber nela plausíveis passos para communitas.

No âmbito da possíbilidade, a CPLP pode ser experienciada como comunidade de fato na medida em que seus sonhos sejam coletivos, isto é, sem condições de pertencer a um dono que estabelce seus avanços e limites, suas áreas e fronteiras. E a chave de leitura para que a CPLP busque se reconhecer como uma communitas está em sua diversidade, tecida nas relações histórico-identitárias as entre as 
nações e nos contatos permanentes entre seus povos, comprometendo uma imaginária lusofonia europeia. A comunidade só pode "realizar-se pela assunção dessa pluralidade e dessa diferença e pelo conhecimento aprofundado de uns e de outros" (Martins, 2006, p. 81).

É claro que não se trata da comunidade perfeita, mas aquela que se constitui nas imperfeições, em construção e reconstrução permanente, ou seja, "inextricavelmente portuguesa, brasileira, angolana, moçambicana, cabo-verdiana ou são-tomense" (Lourenço, 2001: 111), sem traços de centralidade. 0 desafio está posto: não permitir que o ponto de partida e nem uma ilusória unidade linguística enrijeçam a experiência de uma CPLP como comunidade. Em outras palavras, nem sua certidão de nascimento e nem o idioma podem se constituir como identidade, como uma essência, ao contrário, a lusofonia empresta às condições históricas para um abrir-se e comprometer-se.

Um outro aspecto importante é que a ideia democrática de lusofonia precisa ser ampla e circular em toda comunidade, o que obrigará, em algum momento, a discussão sobre os seus laços e as suas amarrações históricas e identitárias entre seus povos. Essa perspectiva vai obrigar a enxergar as dívidas não pagas, especialmente com os países africanos e com Timor Leste, e em parte com o Brasil. Ou seja, poderemos ter uma comunidade que se constrói nas obrigações a cumprir, no dever de reparação, o que nos aproximaria fundamentalmente da communitas. Negros, índios e mestiços esperam retribuição recíproca e fraterna e os dados estatísticos são uma denúncia das extremas desigualdades econômicas e sociais dentro da CPLP, que revelam que essa conta ainda não foi paga e que não pode ser ignorada.

Contraditoriamente, as construções identitárias nos países da CPLP, as condições históricas e a conjuntura contemporânea são potencialidades para a experiência de uma comunidade como communitas, na medida em que impõem a todos, especialmente aos mais desenvolvidos, o dever, a obrigação. A CPLP pode ser um lugar para se exercer uma comunidade de fato, mas é urgente ter em conta as ações de reparação histórica e identitária, a começar pela livre mobilidade entre os povos. Não existe comunidade sem livre acesso, demarcada por fronteiras aparentemente tão fixas e intransponíveis que sequer permite a visibilização do sujeito que pertence ao nós, mas que é fabricado como um outro.

A pesquisa nos jornais $O$ Globo e Folha de $S$. Paulo nos quase 20 anos da CPLP é reveladora de uma não-comunidade, da presença de uma ausência. Pela ótica desses jornais, o Brasil não reconhece a comunidade, não se reconhece nela e quando traz algum registro, em geral, revela alguma relação de "compadrio" com Portugal e de distância e superioridade dos países africanos e de Timor Leste. Para ser pensada como uma communitas é preciso almejar aquilo que faz "aparecer sujeitos que até então não eram contados ou considerados como interlocutores, traz à experiência sensível vozes, corpos e testemunhos que até então não eram vistos como dignos de respeito e estima" (Marques, 2011: 34).

Por isso, um dos primeiros passos para que a CPLP seja experienciada como communitas é romper com as tramas de sua própria invisibilização. A ausência da CPLP nos dois principais jornais brasileiros de referência nos últimos 20 anos faz o Brasil assumir o papel de immunitas, sentindo-se completamente dispensado de deveres para com os povos dessa comunidade. A questão é que, na medida 
em que o Brasil não se reconhece como constituidor dessa comunidade, acaba também sentindo-se desobrigado para com a grande maioria de sua população, que liga-se ao mesmos fios e troncos identitários negros, índios, africanos, mestiços e europeus.

\section{ReFERÊNCIAS BIBLIOGRÁFICAS}

Baptista, M. M. (2006). A lusofonia não é um jardim ou da necessidade de perder o medo às realidades e aos mosquitos. In: Martins, M. et al (Eds.). Comunicação e Lusofonia: Para uma abordagem crítica da cultura e dos media. Porto: Campo das Letras.

Bauman, Z. (2003). Comunidade: a busca por segurança no mundo atual. Rio de Janeiro: Jorge Zahar Editor.

(2005). Identidade. Rio de Janeiro: Jorge Zahar Editor.

Cabecinhas, R. \& Cunha, L. (2003). Colonialismo, identidade nacional e representações do "negro". Estudos do Século XX, v. 3, p. 157-184.

Cabecinhas, R. (2002). Racismo e etnicidade em Portugal: uma análise psicossociológica da homogeneização das minorias. Tese de Doutoramento em Ciências da Comunicação. Universidade do Minho.

Canclini, N. (1997). Culturas híbridas. São Paulo: Edusp.

Cunha, E (2006). Estampas do imaginário: literatura, história e identidade cultural. Belo Horizonte: UFMG.

Esposito, R. (2005). Immunitas: protección y negación de la vida. Buenos Aires: Amorrortu. (2012). Communitas: origen y destino de la comunidad. Buenos Aires: Amorrortu.

Furtado, C. (2007). Formação econômica do Brasil. 34ª ed. São Paulo: Cia das Letras. Giddens, A. (2002) Modernidade e Identidade. Rio de Janeiro: Jorge Zahar Editor.

Hall, S. (2006). A identidade cultural na pós-modernidade. $11^{\text {a }}$ ed. Rio de Janeiro: DP\&A. (2013). Da diáspora: identidades e mediações culturais. $2^{\mathrm{a}}$ ed. Belo Horizonte: UFMG. Ilharco, A \& Murargy, M. (2014). 18 anos CPLP: os desafios do futuro. Lisboa: Sersilito. Instituto Nacional de Estatística. (2015). Estatísticas da CPLP. Lisboa: IME.

Lourenço, E. (2001). A nau de Ícaro e a imagem e miragem da lusofonia. São Paulo: Cia das Letras.

Margarido, A. (2000). A Lusofonia e os lusófonos: novos mitos portugueses. Lisboa: Edições Universitárias Lusófonas.

Marques, A. (2011). Comunicação, estética e política: a partilha do sensível promovida pelo dissenso, pela resistência e pela comunidade. Galáxia, São Paulo, n. 22, p. 25-39.

Martins, M. (2006). A Lusofonia como promessa e o seu equívoco lusocêntrico. In: Martins, M. et al. (Eds.) Comunicação e Lusofonia: Para uma abordagem crítica da cultura e dos media. Porto: Campo das Letras.

Merleau-Ponty, M. (2012). 0 visível e o invisível. São Paulo: Perspectiva.

Mouillaud, M. (1997). O jornal: da forma ao sentido. Brasília: UnB.

Paiva, R. (2012). Novas formas de comunitarismo no cenário da visibilidade total: a comunidade do afeto. Matrizes, São Paulo, no 1, p. 63-75, jul./dez. Disponível em: <http:// www.matrizes.usp.br/index.php/matrizes/article/view/377>. Acessado 02/03/2015. 
Said, E. (2011). Cultura e imperialismo. São Paulo: Cia das Letras.

Santos, M. (2000). Por uma outra globalização: do pensamento único à consciência universal. 2. ed. Rio de Janeiro: Record.

Sodré, M. (2014). A Ciência do comum. Petrópolis/RJ: Vozes.

Sousa Santos, B. de. (1994). Modernidade, identidade e a cultura de fronteira. Tempo Social. São Paulo: USP(Sociologia), n. 5: 31-52. Disponível: <https://estudogeral.sib.uc.pt/ handle/10316/11597> Acessado em 21/02/2014. 